\title{
RSP Revisitada Desenvolvimento da teoria de administração democrática
}

\author{
Dwight Waldo (Tradução de Renata dos Santos Costa; \\ Revisão técnica de João Alberto Tomacheski)
}

A RSP Revisitada disponibilizou, em sua edição anterior, a primeira parte do texto de Dwight Waldo (1913-2000), Desenvolvimento da Teoria de Administraşão Democrática, clássico publicado em março de 1952, na American Political Science Review. Após cerca de 60 anos, esta seção resgata a continuação do ensaio, suprimida quando de sua publicação na edição de 1953 da RSP. O texto apresenta as bases do pensamento e da história administrativa, diante das quais as teorias da administração democrática poderiam ser vistas em relevo. $\mathrm{O}$ artigo passa em revista algumas dessas teorias e autores e reflete sobre perspectivas e problemas do desenvolvimento da teoria da administração democrática.

Sendo a administração o centro do governo moderno, os conceitos democráticos do século 20 foram forjados no sentido de compreender a gestão administrativa. Desta feita, as teses sobre administração democrática, elaboradas entre as décadas de 1940 e 1950, representavam significativo progresso no pensamento político e foram construídas com intuito de se buscar novos caminhos na evolução das doutrinas democráticas.

O ensaio destaca as diversas linhas que o pensamento sobre a democracia e a administração vinha seguindo. Existia, sem dúvida, considerável literatura a cruzar para as velhas divisas entre política e administração, e também a procurar uma adaptação entre a administração e as necessidades da democracia em meados do século 20.

Quais são as possibilidades de um desenvolvimento maior e mais efetivo da teoria democrática na administração? Quais obstáculos estão no caminho de outras conquistas substantivas e por quais métodos eles poderiam ser superados?

A ideia de que a eficiência é um conceito de valor neutro, ou pior ainda, contrário à democracia, é um dos grandes obstáculos no caminho do desenvolvimento da teoria democrática. Sustentar que devemos considerar a eficiência 
como o conceito central de nossa "teoria", mas tolerar um pouco de democracia, uma vez que "acreditamos" nela, é envenenar a nascente da sociedade americana. Para manter a afirmação de que eficiência é um conceito neutro e propor que, ao mesmo tempo, ela seja usada como conceito central em uma "ciência" da administração, é comprometer-se com o niilismo, enquanto a prescrição for seguida ${ }^{27}$.

O declínio avançado da "ortodoxia" na administração pública torna possível, senão inevitável, o desenvolvimento da teoria da administração democrática. Eficiência é, entretanto, um dogma da ortodoxia que tem se recusado a cair. Ninguém mais acredita na separação rigorosa entre política e administração; mas na sugestão de que existam "decisões de valor" e "decisões de fato", e de que decisões de fato podem ser feitas com base na eficiência - uma divisão lógica de realidade que substitui o institucionalismo anterior. Desse ponto de vista, o fato de a administração atual fundir decisões de valores e de fato em apenas uma operação não afeta a validade da distinção lógica; não seria esse o método de a ciência abstrair-se da chamada realidade?

Como remover esse obstáculo do caminho da administração democrática? De certo, não se tentará retirar "eficiência" de nosso vocabulário; esse é um dos conceitos-chave da nossa cultura, logo, não pode ser tratado de maneira tão radical. Seria inútil a tentativa de eliminá-lo completamente como uma "meta" ou medida administrativa. A solução está no uso crescente, sutil e indispensável do termo, discernindo o contexto valorativo no qual o termo é utilizado. Sua atual utilidade como uma ferramenta tosca (crude tool, no original) para medir razão e proporção deve ser reconhecida; mas, por sua vez, o contexto valorativo das coisas nas quais se mede razão e proporção deve ser considerado. Devemos nos perguntar cada vez mais não apenas "Qual é a eficiência de nossos métodos para com nossos resultados?", mas também "Quais são as implicações dos nossos fins para nosso uso dos meios e, como consequência, para nossa medida de eficiência?" É preciso reconsiderar a relação método-resultado, reconhecendo que a escolha e o uso dos meios têm efeito nos resultados. Se assim considerado, podemos certamente esperar que o conceito de eficiência tenha seu significado aperfeiçoado até o final do século XX, da mesma maneira que ocorreu com o conceito de utilidade no século XIX.

É provável que o maior obstáculo ao desenvolvimento da teoria da administração democrática não esteja na excessiva ênfase dada à eficiência, mas, sim, na força de um conjunto de ideias "autoritárias" a respeito das organizações humanas. Por isso, voltaremos nossa atenção para algumas das ideias autoritárias mais importantes, para a natureza dos desafios que elas trazem e, por fim, para uma possível técnica por meio da qual elas podem, por sua vez, ser confrontadas.

Algumas dessas ideias autoritárias incluem aquelas incorporadas nas tradições da administração pública e privada. No setor de negócios da administração priva$\mathrm{da}$, esse autoritarismo refere-se aos "direitos de propriedade" historicamente recebidos e legalmente protegidos, apesar de apoiado por muitas outras fontes, inclusive pela Administração Científica e o Mayoismo $^{28}$. $\mathrm{Na}$ administração pública, o autoritarismo é baseado historicamente em teorias políticas gerais, particularmente aquelas agrupadas ao redor das ideias de soberania. Há também, aqui, um empréstimo considerável de ideias autoritárias da 
administração de negócios. A natureza geral dos problemas colocados por tais ideias autoritárias já foi estudada.

Entretanto, talvez exista uma área mais desafiadora para uma ampla e válida teoria da administração. Essa área pode ser chamada de "Teoria Sociológica". Nos anos recentes, alguns dos trabalhos mais valiosos sobre administração têm sido feitos por aqueles cujo comprometimento formal não é a ciência política, mas a sociologia. Como exemplos destacam-se Reinhard Bendix, Philip Selznick e Robert K. Merton $^{29}$. Acrescentamos que esses escritores têm um apego fervoroso à democracia. No entanto, no centro do tratamento sociológico da organização e da administração, há uma ênfase nos temas da autoridade, do controle, da hierarquia, da disciplina e assim por diante, os quais parecem ser inerentes a todos os grupamentos sociais. Questão que tem sido enfatizada nos trabalhos clássicos de sociologia.

Agora, com certeza, toda sabedoria no desenvolvimento de uma teoria democrática talvez resida no reconhecimento das inevitáveis limitações do material humano. Autoridade e disciplina também devem ser reconhecidas como indispensáveis neste mundo. Entretanto, em grande parte das questões humanas, a história que experimentamos é o resultado dos ideais que buscamos (grifos no original). Em outras palavras, em se tratando de organizações humanas, as coisas não são verdades ou mentiras; o que acontece é "aceito como verdade" ou "aceito como mentira". Uma teoria da administração democrática viável, que não seja superficial e pouco otimista, não deve evitar a literatura da sociologia, nem ser subjugada ou enfraquecida pelo que parece ser seus achados - descobertas essas que, afinal, estão longe de serem generalizações científicas definitivas.
Um exemplo do desafio apresentado pela teoria sociológica contemporânea, e uma ilustração de como o desafio pode ajudar a erguer uma teoria democrática mais sólida, são fornecidos por Philip Selznick em seu estudo da T.V.A. (Tennessee Valley Authority) e sua crítica à democracia "de base" da T.V.A. A tese de Philip Selznick é que o que foi representado por Lilienthal como democracia, o processo de apoio e cooperação dos interesses locais e das organizações, é mais realístico se descrito em outros termos. $\mathrm{Na}$ verdade, argumenta ele, a liderança da T.V.A. barganhou, de modo consciente ou inconsciente, com os centros políticos locais para o apoio ao programa elétrico da T.V.A. O preço desse apoio foi a aceitação, por parte da T.V.A, de todo o padrão remanescente de organização da economia sulista e de suas relações de raça e classe. A incorporação das organizações locais na estrutura da T.V.A. foi meramente a institucionalização desse poder de barganha.

Tendo por base essas evidências, a validade da crítica de Selznick parece claramente estabelecida. Não existe alternativa, a não ser reavaliar de forma crítica as teorias de Lilienthal e a experiência da T.V.A. Provavelmente, algumas ideias úteis podem ser resgatadas. De qualquer maneira, a teoria da organização democrática deve reconhecer a contribuição de Selznick ao ajudar a distinguir teorias válidas das inválidas ${ }^{30}$.

Alguns escritos contemporâneos sobre a teoria da organização devem um grande e óbvio débito a Max Weber e Roberto Michels. O trabalho desses dois homens, muito respeitados e de grande influência, não pode ser esquecido nem mesmo num artigo desse escopo. O trabalho de Weber pertinente para o tema é o ensaio, de profundidade impressionante, traduzido sob 
o título de "Burocracia" 31 Para Weber, "burocracia" não é um termo de descrédito, mas um tipo de organização humana: um tipo caracterizado pela racionalidade, hierarquia, divisão de trabalho, especialização de função, profissionalismo e assim por diante. Ele vê esse tipo de organização como "tecnicamente superior", e percebe sua predominância (tanto na área privada quanto na área pública) como uma característica da idade moderna ocidental. $\mathrm{Na}$ visão de Weber, há uma mistura de admiração pela eficiência da burocracia com uma pequena mágoa de que ela deveria ter triunfado (já que sua racionalidade, se bem-sucedida, recusa a espontaneidade e o jogo livre nas relações humanas). Além do mais, em sua análise, a burocracia, vista em certos aspectos como contrária à democracia, é, de alguma maneira, o fruto natural do desenvolvimento da democracia nos tempos modernos. Essas características da teoria de Weber apresentam um grande desafio para aqueles que defendem a teoria da administração democrática.

Do ponto de vista dessa análise, como Weber pode ser contestado? É razoável argumentar que, apesar de toda sua erudição, Weber foi um produto de seu tempo, e aceitou sem críticas alguns dos valores do ambiente antidemocrático em que vivia. Será a burocracia tecnicamente "superior" um fato atemporal (sub specie aeternitatis) ou apenas o ponto de vista de Max Weber, escrevendo de uma Alemanha ainda Império? E mais, não seria Max Weber uma vítima, talvez, de uma fraqueza comum, aquela de imaginar-se no tempo e no local do fim do processo criativo, com a imagem de uma civilização ocidental que se move vagarosamente em direção ao tipo de organização característica de seu tempo? Resumindo, o teórico da organização democrática deve dar crédito a
Weber por uma imagem útil do seu e dos nossos dias, mas deve se recusar a acreditar que essa seja a melhor de todas as imagens; não deve simplesmente olhar para trás a fim de ver quais tipos de sociedades existiram, mas deve olhar adiante, para o futuro de novos e ainda desconhecidos tipos de sociedades.

Roberto Michels apresenta um tipo diferente de problema, à primeira vista mais difícil, mas, na verdade, mais simples. O foco de sua tese, sua "lei de ferro", quase se choca perigosamente com o ponto central das nossas expectativas. Porém, o "golpe" não é fatal, e, se devidamente tratado, a recuperação é rápida e não deixa vestígios.

De acordo com a "lei de ferro" de Michels, em toda organização, mesmo naquelas mais democráticas ou socialistas, há uma tendência centrípeta, oligárquica, hierárquica: "Os socialistas podem triunfar, mas o socialismo nunca." Michels se mostra vulnerável ao exagero na demonstração de sua tese e na subordinação de tudo à comprovação da mesma. Sem dúvida existem poucos exemplos na história acadêmica de esforços tão intensos para provar um único ponto. $\mathrm{Na}$ verdade, uma devoção cega ao pensamento oposto pode resultar em uma "lei de ferro para a anarquia", a descoberta de que não importa quão rígida uma teoria de autocracia e organização trabalhe; ainda assim, existe uma impressionante (e bem-sucedida) força centrífuga, anti-hierárquica e desintegradora em ação. Consequentemente, teóricos democráticos deveriam procurar utilizar os dados empíricos para argumentar contra qualquer evidência empírica usada para demonstrar a impossibilidade de uma administração democrática ${ }^{32}$.

O nome de Karl Marx também deveria ser mencionado, devido a considerável 
popularidade das ideias marxistas nas ciências sociais do Século XX. Contudo, neste ensaio, será muito difícil avaliar o significado do Marxismo em sua totalidade. Essa dificuldade existe, em parte, devido ao fato de o Marxismo ser ambivalente ou confuso no que diz respeito à administração. $\mathrm{O}$ Marxismo combina $\mathrm{O}$ ódio revolucionário contra a autoridade e "burocracia" do século XIX com a teoria da ditadura do proletariado numa fé ingênua, na crença de que, após a vitória do proletariado, o gerenciamento não seria mais necessário, pois todas as coisas teriam êxito por si só. A dificuldade torna-se ainda maior porque aspectos idênticos do Marxismo são fontes de conclusões contrárias, dependendo do assunto e da pessoa.

Um dos usos das ideias Marxistas, de considerável interesse na visão deste artigo, é encontrado no livro de James Burnham The Managerial Revolution, que criou uma grande agitação quando publicado em 1941, e continua recebendo muitas referências acaloradas. Sua tese afirma que os Marxistas estão corretos em prever o fim inevitável da classe média capitalista, porém errados em presumir que isso será seguido pelo triunfo do proletariado. Ao invés disso, surgirá uma nova classe dominante, de gestores, aqueles que têm o comando da ciência e da tecnologia e, por ora, se encontram no controle da moderna organização de larga escala. $\mathrm{Na}$ verdade, essa classe está surgindo nesse momento e já está, de maneira geral, no controle. Tal argumento recebeu, obviamente, muitas críticas; e muitas das previsões históricas de Burnham, reveladas em estilo grandiloquente, logo tornaram-se absurdas com a marcha real da história.

Ainda assim, há um aspecto da tese de Burnham que não pode ser facilmente ignorado e merece uma atenção maior do teórico democrático. É a ideia de que o controle da tecnologia moderna introduz elementos importantes e novos na relação entre empregador-empregado. (Essa não é uma ideia marxista. Na verdade, ela é contrária ao Marxismo quando afirma que o poder baseia-se em algo que não é o direito à propriedade). Com um impacto chocante, esse tema foi desenvolvido no livro 1984, de George Orwell: a sociedade dirigente é tecnicamente perfeita, embora moralmente depravada - é tirânica, não conhece limites e é eterna. Contudo, o meio que a tecnologia moderna fornece para a tirania produz não apenas uma ameaça à teoria da administração democrática, mas também gera uma oportunidade. Tendo em vista que as instituições democráticas tradicionais são inadequadas para a tarefa, a proteção à sociedade contra o uso inadequado dos instrumentos, sob os quais ela vive, deve vir do desenvolvimento de novas instituições e ideias.

Mas o desafio central apresentado pelo Marxismo em si, em uma sociedade não marxista, é saber se uma teoria da administração democrática pode abolir ou mitigar o controle de alguns seres humanos sobre os outros, numa sociedade onde os meios de produção são de propriedade privada. Esse é um desafio que será difícil de ser encarado, precisamente porque, em uma sociedade na qual a propriedade privada é a regra, há, de fato, uma grande parcela de controle de alguns seres humanos sobre outros; e não há elaborações ou invenções da teoria democrática que sejam capazes de mudar essa situação rapidamente. Essas elaborações e invenções em curso no reino das ideias, bem como as expectativas de mudanças institucionais, sustentam a tese da dificuldade de mudança na situação atual, e o teórico democrático deve, talvez, se contentar em negar a troca de um 
autoritarismo pelo outro. Em Michels e em Pareto, apenas para citar dois nomes, encontraremos uma grande quantidade de argumentos mostrando que o controle de muitos por poucos não é desfeito com o simples expediente de abolição da propriedade privada. Encontraremos uma grande variedade de dados empíricos para a demonstração desses argumentos.

O problema central da teoria da administração democrática, bem como em toda a teoria política democrática, é como reconciliar o desejo de democracia (liberdade é um conceito muito estreito) com as demandas de autoridade. Ideias férteis de como se fazer essa reconciliação com sucesso são encontradas em alguns escritos não publicados de William Brownrigg. Brownrigg é um consultor de gestão que se dedicou com afinco à tarefa de tentar encontrar um quadro conceitual para o estudo e a prática da administração. Seu objetivo explicitado não é a democracia, mas a cooperação e a eficiência. Porém, talvez seu quadro conceitual possa ao menos prover algumas indicações para uma melhor solução do problema da administração democrática.

Em busca dos aspectos básicos da administração, Brownrigg (assim como muitos outros) conclui que a administração não passa de uma categoria e que, para entender seus fundamentos, é preciso ir além disso. A maior parte dos estudantes, perseguindo tal análise abstrata, se contenta com a "organização" como um conceito básico, mas Brownrigg prefere utilizar como ideia central "o processo de empreendimento humano", no qual a administração ou a burocracia se constitui na principal forma característica desse processo atualmente. Seguindo sua análise, conclui que todos os empreendimentos humanos têm três aspectos, a saber: decisão, administração e utilização. Cada um dos três é, então, analisado a partir de um número de passos ou processos que podem caracterizá-los num complexo empreendimento social. Brownrigg fala dos três aspectos básicos como três elos da mesma corrente, cada um ligado ao outro, e vê o processo administrativo mais como circular do que linear. De fato, em sua concepção, a administração toca em sutilezas e dimensões que não podem sequer ser aludidas por dispositivos tais como gráficos de função organizacional. Grandes empreendimentos são, em verdade, grandes complexos de empreendimentos lógicos; e nesse processo, não existe uma simples dicotomia entre gestores e gerenciados, e sim o fato de todos os participantes, em diferentes graus e situações, serem decisores, administradores e usuários.

O que é intrigante a respeito dessa concepção é que, se há uma validade essencial nela, é possível um abandono dos padrões de pensamento da relação autoridade-submissão, supervisor-subordinado, que tendem a dominar nossa teoria da administração. Certamente, algumas das tensões e problemas de nossos dias resultam do "atraso cultural" entre as demandas e possibilidades de organizações de larga escala e as ideias tradicionais herdadas.

Em raros momentos de otimismo, alguns se permitem o luxo de sonhar com uma sociedade do futuro, na qual a educação ${ }^{33}$ e a cultura geral estejam em harmonia com o funcionamento do mundo, no qual todos participem como "líderes" e "seguidores", de acordo com as "regras do jogo" conhecidas por todos. Essa seria a sociedade pós-burocrática. A burocracia no sentido Weberiano seria substituída por formas de organizações em larga escala mais democráticas e flexíveis, apesar de mais complexas. A cultura como um todo seria 
adaptada para a organização pós-burocrática, da mesma maneira como foi adaptada e apoiada pela organização burocrática na Alemanha de Weber. A autoridade teria ainda um papel legítimo nesta sociedade, por ser um aspecto de todas as sociedades.

Mas o axioma fundamental da mecânica social dessa sociedade do futuro seria: A unica coisa capaz de legitimar a autoridade numa sociedade democrática é a democracia em $\mathrm{si}^{34}$. Como uma questão de formalização teórica, prosseguimos agora com essa ideia em nossa vida pública, apesar de a institucionalização tradicional da ideia estar cada vez mais obsoleta no século XX. Em nossa vida privada, nós a reconhecemos como muito inadequada, e em nossa atividade econômica, pouco a reconhecemos. E na distância entre a teoria geral da vida e os fatos de nosso cotidiano, existe uma grande tensão cultural e uma tragédia pessoal. É verdade que essa sociedade pós-burocrática não buscaria a visão utópica (ou o pesadelo do totalitarismo) de total falta de conflito. Uma considerável dose de conflito é, talvez, não só necessária, mas socialmente desejável; a estrutura de qualquer sociedade democrática deve ser feita de maneira a permitir a existência do conflito, sem que esse comprometa a própria estrutura.

\section{Notas}

${ }^{27}$ Nessa disputa, o presente "peso de autoridade" está contra mim. Mas creio que não há campos de "decisões factuais" dos quais os valores sejam excluídos. Decidir é escolher entre alternativas, escolher entre alternativas é introduzir valores. Herbert Simon tem feito grandes contribuições ao estudo administrativo. Essas contribuições foram feitas, entretanto, quando ele trabalhava livre da metodologia da qual ele defende.

${ }^{28} \mathrm{O}$ quanto esse autoritarismo ainda está firmemente enraizado, é indicado por um artigo de Robert Tannenbaum, denominado "The Manager Concept: A Rational Synthesis", Journal of Business of the University of Chicago, Vol. 22, pp. 224-41 (Out., 1949).

${ }^{29}$ Veja Reinhard Bendix, "Bureaucracy and the Problem of Power," Public Administration Review, Vol. 5, pp. 194-209 (Verão, 1945), e “Bureaucracy: The Problem and Its Setting," American Sociological Review, Vol. 12, pp. 493-507 (Out., 1947); Philip Selznick, "An Approach to a Theory of Bureaucracy," American Sociological Review, Vol. 8, pp. 25-35 (Feb., 1948), e T.V.A. and the Grass Roots (Berkeley, 1949); R. K. Merton, "Bureaucratic Structure and Personality," Social Forces, Vol. 18, pp. 561-68 (Mai, 1940), e "Role of the Intellectual in Public Bureaucracy," Social Forces, Vol. 23, pp. 405-15 (Mai., 1945).

${ }^{30}$ Cf R. G. Tugwell and E. C. Banield, "Grass Roots Democracy Myth or Reality?” Public Administration Review, Vol. 10, pp. 47-55 (Winter, 1950). Em minha opinião, precisamos de estudos similarmente críticos, com todos os experimentos em administração que se apresentaram como "democracia na administração". Sem dúvida alguns desses são apenas interesses próprios disfarçados. Não se faz democracia delegando às raposas todas as decisões sobre as galinhas. Para uma revisão sobre alguns dos experimentos "democráticos", ver John D. Lewis, "Some New Forms of Democratic Participation in American Government.”, J. B. Shannon (ed.), The Study of Comparative Government (New York, 1949). 
${ }^{31}$ Em Max Weber: Ensaios sobre Sociologia, trad e ed. H. H. Gerth and C. Wright Mills (New York, 1946).

${ }^{32}$ Algumas indicações de como uma teoria da administração democrática pode ser sustentada por dados empíricos, ainda experimentais, podem ser encontradas em Robert Tannenbaum e Massarik Fred, "Participation by Subordinates in the Managerial Decision-Making Process", reimpresso pelo Canadian Journal of Economics and Political Science n ${ }^{\circ}$. 14, Institute of Industrial Relations, University of California, Los Angeles. Apesar de os autores estarem preocupados com a "participação como processo gerencial”, algumas de suas sugestões podem ser usadas para outros propósitos.

${ }^{33}$ Significativamente, o The New State tem um apêndice intitulado "The training for the New Democracy". É claro que uma teoria da administração democrática deve eventualmente lidar com educação - educação para a participação na administração democrática. Na verdade, os escritos de psicólogos, indicando que o "complexo supervisor-subordinado" de um indivíduo está enraizado na sua vida familiar, sugerem um escopo maior para uma teoria da administração democrática.

${ }^{34}$ Muito relacionado ao tema, temos o trabalho de Peter Drucker, que tem escrito perceptivamente sobre muitos aspectos da reconstrução da sociedade para fazê-la compatível com as organizações de grande escala. Em The New Society; The Anatomy of Industrial Order (New York, 1950), Druker, de forma correta, enuncia um problema central: como se pode legitimar o poder de organizações industriais de grande escala em um período no qual os direitos de propriedade não se legitimam em si mesmos? Sua resposta, apesar de todos os refinamentos, é a tradicional: uma linha deve ser traçada entre uma área governamental, na qual a democracia é aplicável, e uma área econômica, na qual ela não é. A integridade da "gestão" deve ser preservada e, no máximo, empregados devem ter uma participação na operação de serviços de assistência ao empregado. 